\title{
ANALISIS PENGARUH INSENTIF TERHADAP KINERJA PELAYANAN PUBLIK PADA PEGAWAI RUMAH SAKIT JIWA KENDARI
}

\section{Analysis of the Effect of Incentives on the Performance of Public Services on Mental Hospital Employees Kendari}

\author{
Muarif Leo \\ Email : Muarifleo123@gmail.com \\ Prodi D-IV Keuangan Publik/ Jurusan Ekonomi \& Bisnis/ Politeknik Baubau \\ Politeknik Baubau, Jl. Lakarambau, Kota Baubau, 93721, Sulawesi Tenggara, Indonesia
}

\begin{abstract}
ABSTRAK
Tujuan penelitian adalah untuk mengetahui, menguji dan mengukur pengaruh insentif terhadap kinerja pelayanan publik pada pegawai Rumah Sakit Jiwa Kota Kendari. Rancangan penelitian yang digunakan adalah penelitian kuantitatif. Populasi dalam penelitian ini adalah pegawai Dinas Rumah Sakit Jiwa Kota Kendari sebanyak 68 orang, dengan menggunakan penarikan sampel menggunakan proportionate random sampling Pengambilan data berupa metode wawancara dan kuesioner. Adapun teknik analisi data menggunakan model regresi berganda dengan bantuan software SPSS 24. Hasil penelitian menunjukkan bahwa insentif yang terdiri dari insentif materi dan insentif non materi berpengaruh signifikan terhadap kinerja pelayanan publik di Dinas Rumah Sakit Jiwa Kota Kendari.
\end{abstract}

Kata Kunci : Insentif dan Kinerja Pelayanan Publik.

\section{ABSTRACT}

The purpose of this research is to find, test and measure the effect of incentives on the performance of public services to the employees of Kendari City Mental Hospital. The design of the study is a quantitative research. The population in this study were employees of the Department of Mental Hospital of Kendari as many as 68 people, using proportionate random sampling using sampling Retrieval of data in the form of interviews and questionnaires. The technique of data analysis using multiple regression models with SPSS 24. The results showed that the incentives consist of material incentives and nonmaterial incentives have a significant effect on the performance of public services in the Department of Mental Hospital of Kendari.

Keywords : Incentive and Performance of Public Services.

\section{PENDAHULUAN}

Kinerja pegawai sangatlah harus diperhatikan karena merupakan salah satu kunci keberhasilan. Apabila suatu instansi melakukan aktivitas instansi pemerintah dengan kinerja yang kurang baik maka citra instansi akan kurang baik. Menurut Undang-Undang Nomor 8 tahun 1974 tentang pokok-pokok kepegawaian yang kemudian diubah menjadi Undang-Undang Nomor 43 tahun 1999 memberikan pengertian bahwa pegawai Negara adalah setiap Warga Negara Republik Indonesia yang telah memenuhi syarat yang 
ditentukan, diangkat oleh pejabat yang berwenang dan diserahi tugas Negara lainnya dan digaji berdasarkan peraturan perundang-undangan yang berlaku. Kinerja adalah hasil pelaksanaan suatu pekerjaan,baik bersifat fisik atau material maupun non-fisik atau nonmaterial (Hadari Nawawi, 2005). Kemudian Moeheriono, (2010) menjelaskan bahwa kinerja adalah hasil kerja yang dapat dicapai oleh seseorang atau kelompok orang dalam suatu organisasi baik secara kuantitatif, sesuai dengan kewenangan dan tugas tanggung jawab masing-masing, dalam upaya mencapai tujuan organisasi yang bersangkutan secara legal, tidak melanggar hukum dan sesuai dengan moral atau etika.

Menurut Handoko (2002) menyatakan bahwa pengertian insentif adalah : "Perangsang yang ditawarkan kepada para karyawan untuk melaksanakan kerja sesuai atau lebih tinggi dari standar-standar yang telah ditetapkan”. Sedangkan Pangabean (2002) Insentif adalah kompensasi yang mengaitkan gaji dengan produktivitas, insentif merupakan penghargaan dalam bentuk uang yang diberikan kepada mereka yang dapat bekerja melampaui standar yang telah ditentukan. Rumah Sakit Jiwa di Sulawesi Tenggara khususnya Rumah Sakit Jiwa Kota Kendari merupakan institusi pemerintahan dalam bidang kesehatan khususnya pada bidang ganguan mental, menyelenggarakan pelayanan kesehatan secara paripurna yang menyediakan pelayanan yaitu : rawat inap, rawat jalan, serta gawat darurat (UGD). Rumah Sakit Jiwa Kota Kendari memiliki tugas menyelengarakan dan melaksanakan pelayanan pencegahan, pemulihan dan rehabilitasi di bidang kesehatan jiwa. Pemberian insentif akan kinerja yang optimal dan maksimal terhadap pegawai diterapkan juga oleh instansi Rumah Sakit Jiwa Kota Kendari. Berdasarkan observasi yang dilakukan penulis selama beberapa waktu, masih terdapat fenomena yang ada di kantor Rumah Sakit Jiwa Kota Kendari diantaranya ialah sebagai berikut : a.) Ketidak seriusan beberapa pegawai dalam bekerja, terkadang ditemui pegawai yang bekerja sambil berbincang-bincang, akibatnya pekerjaan jadi lambat dan terbengkalai sehingga rasa tanggung jawab dalam melaksanakan tugasnya menjadi menurun. b.) Kurangnya ketepatan waktu dalam penyelesaian suatu pekerjaan. c.) Beberapa pegawai yang bekerja hanya kalau ada tugas dari pimpinan, mereka tidak secara mandiri menyelesaikan pekerjaan dengan baik dan cepat. d.) seringnya para pegawai meninggalkan kantor pada jam-jam kerja dalam rentan waktu yang cukup lama. Fenomena lain yang terjadi penelitian ini adalah masih rendahnya kinerja yang dimiliki oleh pegawai pada Dinas Rumah Sakit Jiwa Kendari yang di tandai dengan masih terdapat hasil kerja pegawai yang tidak sesuai dengan unsur penilaian kurangnya yaitu kualitas kerja, kuantitas dan 
ketepatan waktu dalam penyelesaian pekerjaan sehingga pimpinan harus memberi teguran terhadap pegawai tersebut. Berdasarkan penjelasan diatas, maka penulis memiliki ketertarikan untuk melakukan penelitian dengan judul: "Analisis Pengaruh Insentif Terhadap Kinerja Pelayanan Publik Pada Rumah Sakit Jiwa Kendari".

\section{METODE PENELITIAN}

Jenis penelitian yang dilakukan adalah penelitian kuantitatif. Lokasi penelitian ini akan dilakukan pada Rumah Sakit Jiwa Kendari yang beralamat di Jl. Dr. sutomo No. 29 Kendari. Dan objek penelitian ini adalah Insentif sebagai variabel independen dan kinerja sebagai variabel dependen. Jenis data yang di gunakan dalam penelitian ini adalah (1) data kuantitatif, yaitu data yang diperoleh dari kantor Rumah Sakit Jiwa Kendari yang relevan dengan judul skripsi yang diambil oleh peneliti dan berupa data angka-angka yang dinyatakan dalam berbagai satuan. (2) data kualitatif, yaitu data yang dinyatakan dalam bentuk pernyataan dan jawaban kuesioner. Adapun populasi dalam penelitian ini adalah seluruh pegawai pada Rumah sakit Jiwa Kendari berjumlah 208 orang. Adapun sampel dalam penelitian ini, penulis menggunakan teknik Random Sampling, teknik ini digunakan karena populasinya tidak homogen, mengacu pada pendapat Sugiyono (2011) bahwa, Random Sampling digunakan bila populasi mempunyai anggota atau unsur yang tidak homogen dan berstrata secara proporsional". Dalam penelitian ini penentuan pengambilan sampel dilakukan dengan menggunakan rumus slovin. Berdasarkan rumus tersebut dapat dihitung sampel dari populasi berjumlah 208 orang dengan tarif kesalahan 10\%, maka sampel dalam penelitian ini berjumlah 68 responden.

a. Uji Instrumen

\section{Uji Validitas}

Validitas adalah suatu ukuran yang menunjukkan tingkat-tingkat kevalidan atau kesahihan sesuatu instrumen (Arikunto, 2002: 144). Sebuah instrumen dikatakan valid apabila mampu mengukur apa yang diinginkan dan dapat mengungkap data dari variabel yang diteliti secara tepat.Tinggi rendahnya validitas instrumen menunjukkan sejauh mana data yang terkumpul tidak menyimpang dari gambaran tentang validitas yang dimaksud. Uji validitas instrumen dilakukan dengan menggunakan koefisien korelasi product moment dengan kriteria pengujian pada instrumen yang dikatakan valid jika nilai $\mathrm{r} \geq$ 0,30 (cut of point) atau dalam taraf signifikansi $95 \%$ atau $\alpha=0,05$. (Sugiyono, 2010).

\section{Uji Reliabel}


Uji reliabilitas adalah ukuran mengenai konsistensi internal dari indikator-indikator sebuah konstruk yang menunjukkan derajat sampai dimana masing-masing indikator variabel mengidentifikasi sebuah faktor laten yang umum. Uji reliabilitas bertujuan untuk mengetahui konsistensi alat ukur jika digunakan untuk mengukur objek yang sama lebih dari sekali. Dengan kata lain uji reliabilitas ini dapat diartikan sebagai tingkat kepercayaan terhadap hasil pengukuran. Pengujian reliabilitas dilakukan terhadap item pernyataan yang digunakan dalam penelitian ini adalah dengan metode Alpha Cronbach. Nilai batas (cut of point) yang diterima untuk tingkat Alpha Cronbach adalah $\geq 0,60$ walaupun ini bukan merupakan standar absolut oleh Uma Sekaran (2003). Instrumen dianggap telah memiliki tingkat keandalan yang dapat diterima, jika nilai koefisien reliabilitas yang terukur adalah $\geq 0,60$. Instrumen dikatakan reliabel jika dapat digunakan untuk mengukur variabel berulangkali yang akan menghasilkan data yang sama atau hanya sedikit bervariasi Cooper dan Sehindler (2003).

b. Analisis Regresi Linear Sederhana

Metode yang digunakan untuk mengestimasi parameter model regresi sederhana adalah metode kuadrat terkecil atau disebut juga metode ordinary least square (OLS). Metode OLS bertujuan meminimumkan jumlah kuadrat error (Gujarati, 2003:124).

1. Persamaan Regresi

Persamaan statistik yang digunakan adalah;

$$
\mathrm{Y}=\alpha+\beta 1 X 1 \ldots .+\beta n X n+e
$$

Dimana: Y

$$
\begin{array}{ll}
\alpha & =\text { konstanta } \\
\beta_{1}, \beta_{2} & =\text { koefisien regresi } \\
\mathrm{X}_{1} & =\text { Insentif } \\
\mathrm{e} & =\text { error }
\end{array}
$$

\section{Uji t (Uji Secara Parsial)}

Pengujian ini bertujuan untuk melihat pengaruh dari masing-masing variabel bebas terhadap variabel terikat. Uji $t$ dilakukan dengan membandingkan antara $t$ hitung dengan $t$ tabel. Nilai t hitung ditentukan dengan tidak memperhatikan nilai positif atau negatif dari nilai $\mathrm{t}$ hitung tersebut karena nilai $\mathrm{t}$ hitung merupakan nilai mutlak $|\mathrm{t}|$. Nilai $\mathrm{t}$ yang positif atau negatif merupakan arah dari pengaruh variabel independen tersebut baik itu berbanding lurus (positif) ataupun berbanding terbalik/berlawanan (negatif) terhadap nilai variabel terikat. Dan untuk menentukkan nilai t tabel ditentukkan nilai tabel terikat. Dan 
untuk menentukkan nilai t tabel ditentukkan dengan tingkat signifikansi 5\% dengan derajat kebebasan $d f=(n-k)$ dimana $n$ adalah jumlah responden dan $k$ adalah jumlah variabel. Kriteria pengujian yang digunakan adalah :

- Bila nilai $t_{\text {hitung }}>\mathrm{t}_{\text {tabel }}$ atau nilai signifikansi $<\alpha=0,05$ berarti variabel bebas mempunyai pengaruh secara parsial terhadap variabel terikat.

- Bila nilai $t_{\text {hitung }}<\mathrm{t}_{\text {tabel }}$ atau nilai signifikansi $>\alpha=0,05$ berarti variabel bebas tidak mempunyai pengaruh secara parsial terhadap variabel terikat.

\section{Uji Determinan $\mathrm{R}^{2}$}

Koefisien determinasi merupakan suatu ukuran yang penting dalam regresi, karena dapat menginformasikan baik tidaknya model regresi yang terestimasi. Nilai koefisien determinasi $\left(\mathrm{R}^{2}\right)$ ini mencerminkan seberapa besar variasi dari variabel terikat $\mathrm{Y}$ dapat diterangkan oleh variabel bebas X. Bila nilai koefisien determinasi sama dengan 0 $\left(\mathrm{R}^{2}=0\right)$, artinya variasi dari $\mathrm{Y}$ tidak dapat diterangkan oleh $\mathrm{X}$ sama sekali. Sementara bila $\mathrm{R}^{2}=1$, artinya variansi dari $\mathrm{Y}$ secara keseluruhan dapat diterangkan oleh $\mathrm{X}$. Dengan kata lain bila $\mathrm{R}^{2}=1$ maka semua titik pengamatan berada tepat pada garis regresi. Dengan demikian baik buruknya suatu persamaan regresi ditentukan oleh $\mathrm{R}^{2}$ yang mempunyai nilai antara nol dan satu. (Ghazali, 2011).

\section{HASIL DAN PEMBAHASAN}

\section{a. Karakteristik Responden}

Hasil menunjukkan bahwa sebagian besar responden (45 persen) adalah pegawai yang berusia 40 tahun keatas. Hal ini menunjukkan pegawai dengan usia yang produktif dan memiliki pengalaman dalam menjalankan tugas dan tanggung jawabnya. Hasil ini sesuai dengan pendapat Robbins (2003) menyatakan bahwa,semakin tua usia seseoramg, makin tinggi komitmennya terhadap organisasi, hal ini disebabkan karena kesempatan individu untuk mendapatkan pekerjaan lain menjadi lebih terbatas sejalan dengan meningkatnya usia. Keterbatasan tersebut dipihak lain dapat meningkatkan persepsi yang lebih positif mengenai atasan sehingga dapat meningkatkan motivasi dan profesionalisme kerja. sebagian besar responden (40 persen) adalah berjenis kelamin perempuan. Responden dalam hal ini adalah pegawai Dinas Rumah Sakit Jiwa dengan jumlah sampel 68 orang sebagai berikut: 
Tabel 1.1 Karakteristik Responden Penelitian

\begin{tabular}{|c|c|c|c|}
\hline Karakteristik Responden & & Frekuensi (orang) & Persentase $(\%)$ \\
\hline \multirow[t]{5}{*}{ 1. Umur } & $26-30$ & 2 & 2 \\
\hline & $31-35$ & 15 & 15 \\
\hline & $36-40$ & 6 & 6 \\
\hline & $40 \mathrm{ke}$ atas & 45 & 45 \\
\hline & Jumlah & 68 & 100 \\
\hline \multirow[t]{4}{*}{ 2. Jenis Kelamin } & & Frekuensi (orang) & Persentase (\%) \\
\hline & Laki-laki & 28 & 28 \\
\hline & Perempuan & 40 & 40 \\
\hline & Jumlah & 68 & 100 \\
\hline \multirow[t]{5}{*}{ 3. Masa kerja } & & Frekuensi (orang) & Persentase $(\%)$ \\
\hline & $1-5$ tahun & 15 & 15 \\
\hline & 6-10 tahun & 8 & 8 \\
\hline & 10 keatas & 45 & 45 \\
\hline & Jumlah & 68 & 100 \\
\hline \multirow[t]{6}{*}{ 4. Tingkat Pendidikan } & & Frekuensi (orang) & Persentase (\%) \\
\hline & SMA & 4 & 4 \\
\hline & DIII (Diploma) & 4 & 4 \\
\hline & S1 (Strata 1) & 49 & 49 \\
\hline & S2 (Strata 2) & 11 & 11 \\
\hline & Jumlah & 68 & 100 \\
\hline
\end{tabular}

Sumber: Data primer diolah tahun 2019

Hal ini mengindikasikan bahwa jumlah pegawai perempuan lebih dominan daripada tenaga pegawai laki-laki. Dimana komunikasi pegawai wanita lebih efektif kepada masyarakat dalam meningkatkan kinerjanya. Fakta ini didukung oleh pendapat Robbins (2003) menyatakan bahwa tidak ada perbedaan yang konsisten antara laki-laki dan perempuan dalam kemampuan memecahkan masalah, keterampilan analisis, dorongan kompetitif, motivasi. Sosiabilitas atau kemampuan belajar. Namun studi - studi psikologi telah menemukan bhawa kaum perempuan lebih bersedia untuk mematuhi wewenang dan pria lebih agresif. Bukti yang konsisten juga menyatakan bahwa kaum perempuan mempunyai tingkat ketelitian dan kesabaran yang tinggi daripada pria. sebagian besar responden (45 persen) adalah pegawai dengan masa kerja 10 tahun keatas. Hal ini dikarenakan Dinas Rumah Sakit Jiwa Kota Kendari memiliki tenaga pegawai yang sudah lama dan berpengalaman dalam menjalankan tugas dan tanggung jawabnya. Hubungan pengalaman kerja dengan produktivitas, Robbins (2003) menyatakan bahwa orang-orang yang lebih lama bekerja pada organisasi akan lebih produktif dibandingkan dengan orangorang yang lama kerjanya lebih rendah. Hasil penelitian ini didukung oleh pendapat, Robbins (2003) yang mengemukakan bahwa semakin lama seseorang mengeluti pekerjaan, semakin member dia peluang untuk menerima tugas-tugas yang lebih menantang, otonomi 
yang lebih besar dan keleluasan bekerja. sebagian besar responden ( 49 persen) adalah lulusan S1 (Strata 1). Hal ini sesuai dengan kebutuhan Rumah Sakit Jiwa Kota Kendari, dimana proses rekruitmennya membutuhkan tenaga pegawai minimal sarjana S1 dikarenakan diperlukan tenaga pegawai yang mempunyai pengetahuan dan wawasan yang baik dengan tingkat kepercayaan diri yang tinggi. Para pegawai dengan tingkat pendidikan yang tinggi mampu bekerja dengan tingkat kesulitan dan tanggung jawab yang tinggi sehingga dapat memenuhi kebutuhan konsumen (Robbins 2003).

\section{b. Deskripsi Kuesioner Penelitian}

Insentif adalah suatu sarana memotivasi berupa materi, yang diberikan sebagai suatu perangsang ataupun pendorong dengan sengaja kepada para pekerja agar dalam diri mereka timbul semangat yang besar untuk meningkatkan produktivitas kerjanya dalam organisasi. (Sarwoto (2010:156). Insentif diukur dengan 2 indikator dan 8 item yang meliputi insentif materi dan insentif non materi. Rekapitulasi jawaban responden terhadap pelatihan diuraikan sebagai berikut:

Tabel 1.2 Deskripsi Jawaban Terhadap Variabel Insentif (X1)

\begin{tabular}{|c|c|c|c|c|c|c|c|c|c|c|c|c|c|}
\hline \multirow{2}{*}{$\begin{array}{l}\text { Indikator } \\
\text { variabel }\end{array}$} & \multirow{2}{*}{$\begin{array}{l}\text { Item } \\
\text { Butir }\end{array}$} & \multicolumn{10}{|c|}{ Frekuensi (f) dan Persentase (\%) Jawaban Responden } & \multirow{3}{*}{\multicolumn{2}{|c|}{$\begin{array}{l}\text { Rerata } \\
\text { (Mean) }\end{array}$}} \\
\hline & & \multicolumn{2}{|c|}{ STS (1) } & \multicolumn{2}{|c|}{ TS (2) } & \multicolumn{2}{|c|}{$\mathrm{N}(3)$} & \multicolumn{2}{|c|}{ S (4) } & \multicolumn{2}{|c|}{ SS (5) } & & \\
\hline \multirow{5}{*}{$\begin{array}{c}\text { Insentif } \\
\text { materi } \\
(\mathrm{X} 1.1)\end{array}$} & & $\mathrm{F}$ & $\%$ & $\mathrm{f}$ & $\%$ & $\mathrm{f}$ & $\%$ & $\mathrm{f}$ & $\%$ & $\mathrm{f}$ & $\%$ & & \\
\hline & X1.1.1 & 0 & 0,00 & 0 & 0,00 & 2 & 2,90 & 20 & 29,4 & 46 & 67,6 & 4,65 & \multirow{4}{*}{4,61} \\
\hline & $\mathrm{X} 1.1 .2$ & 0 & 0,00 & 0 & 0,00 & 1 & 1,50 & 22 & 32,4 & 45 & 66,2 & 4,65 & \\
\hline & X1.1.3 & 0 & 0,00 & 0 & 0,00 & 2 & 2,90 & 22 & 32,4 & 44 & 64,7 & 4,62 & \\
\hline & X1.1.4 & 0 & 0,00 & 0 & 0,00 & 2 & 2,90 & 28 & 41,2 & 38 & 55,9 & 4,53 & \\
\hline \multirow{5}{*}{$\begin{array}{c}\text { Insentif } \\
\text { non materi } \\
(\mathrm{X} 1.2)\end{array}$} & $\mathrm{X} 1.2 .1$ & 0 & 0,00 & 0 & 0,00 & 4 & 5,90 & 20 & 29,4 & 44 & 64,7 & 4,59 & \multirow{5}{*}{4,55} \\
\hline & $\mathrm{X} 1.2 .2$ & 0 & 0,00 & 0 & 0,00 & 1 & 1,50 & 32 & 47,1 & 35 & 51,5 & 4,50 & \\
\hline & $\mathrm{X} 1.2 .3$ & 0 & 0,00 & 0 & 0,00 & 1 & 1,50 & 26 & 38,2 & 41 & 60,3 & 4,59 & \\
\hline & X1.2.4 & 0 & 0,00 & 0 & 0,00 & 2 & 2,90 & 29 & 42,6 & 37 & 54,4 & 4,51 & \\
\hline & & \multicolumn{10}{|c|}{ Rerata Variabel Insentif (X1) } & 4,58 & \\
\hline
\end{tabular}

\section{Sumber: Data Primer (Kuisioner) diolah, tahun 2019}

Berdasarkan rekapitulasi pernyataan atas variabel insentif (X1) pada Dinas Rumah Sakit Jiwa Kota Kendari seperti yang disajikan pada Tabel 1.2 diatas, menunjukkan bahwa deskripsi jawaban responden secara keseluruhan tentang insentif termasuk dalam kategori sangat setuju/sangat baik dengan nilai rerata 4,58 yang berada pada interval $(4,21-5,0)$. Artinya bahwa mayoritas responden menyatakan secara keseluruhan mengenai insentif meliputi: insentif material dan insentif non material sebagai hasil dalam meningkatkan semangat kinerja pada pelayanan publik.

Selanjutnya pembahasan mengenai kinerja pelayanan publik adalah sebagai efektivitas organisasi secara menyeluruh untuk kebutuhan yang ditetapkan darisetiap kelompok yang berkenaan melalui usaha-usaha yang sistemik danmeningkatkan 
kemampuan organisasi secara terus menerus untuk mencapaikebutuhannya secara efektif. (Dwiyanto dalam Pasalong (2010:178). Kinerja pelayanan publik diukur dengan 5 indikator dan 15 item yang meliputi; produktivitas, kualitas layanan, responsivitas, responsibilitas dan akuntabilitas. Rekapitulasi jawaban responden terhadap kinerja pelayanan publik diuraikan sebagai berikut:

\section{Tabel 1.3}

Deskripsi Jawaban Terhadap Variabel Kinerja Pelayanan Publik (Y)

\begin{tabular}{|c|c|c|c|c|c|c|c|c|c|c|c|c|c|}
\hline \multirow{3}{*}{$\begin{array}{c}\text { Indikator } \\
\text { variabel }\end{array}$} & \multirow{3}{*}{$\begin{array}{l}\text { Item } \\
\text { Butir }\end{array}$} & \multicolumn{10}{|c|}{ Frekuensi (f) dan Persentase (\%) Jawaban Responden } & \multirow{3}{*}{\multicolumn{2}{|c|}{$\begin{array}{l}\text { Rerata } \\
\text { (Mean) }\end{array}$}} \\
\hline & & \multicolumn{2}{|c|}{ STS (1) } & \multicolumn{2}{|c|}{ TS (2) } & \multicolumn{2}{|c|}{$\mathrm{N}(3)$} & \multicolumn{2}{|c|}{$\mathrm{S}(4)$} & \multicolumn{2}{|c|}{ SS (5) } & & \\
\hline & & $\mathrm{F}$ & $\%$ & $\mathrm{f}$ & $\%$ & $\mathrm{f}$ & $\%$ & f & $\%$ & $\mathrm{f}$ & $\%$ & & \\
\hline \multirow{3}{*}{$\begin{array}{l}\text { Produktivitas } \\
\text { (Y1) }\end{array}$} & Y1.1 & 0 & 0,00 & 0 & 0,00 & 4 & 5,90 & 20 & 29,4 & 44 & 64,7 & 4,59 & \multirow{3}{*}{4,56} \\
\hline & Y1.2 & 0 & 0,00 & 0 & 0,00 & 1 & 1,50 & 32 & 47,1 & 35 & 51,5 & 4,50 & \\
\hline & Y1.3 & 0 & 0,00 & 0 & 0,00 & 1 & 1,50 & 26 & 38,2 & 41 & 60,3 & 4,59 & \\
\hline \multirow{3}{*}{$\begin{array}{c}\text { Kualitas } \\
\text { Layanan (Y2) }\end{array}$} & Y2.1 & 0 & 0,00 & 0 & 0,00 & 5 & 7,40 & 39 & 57,4 & 24 & 35,3 & 4,28 & \multirow{3}{*}{4.43} \\
\hline & Y 2.2 & 0 & 0,00 & 0 & 0,00 & 3 & 4,40 & 27 & 39,7 & 38 & 55,9 & 4,51 & \\
\hline & Y 2.3 & 0 & 0,00 & 0 & 0,00 & 2 & 2,90 & 29 & 42,6 & 37 & 54,4 & 4,51 & \\
\hline \multirow{3}{*}{$\begin{array}{l}\text { Responsivitas } \\
\text { (Y3) }\end{array}$} & Y3.1 & 0 & 0,00 & 0 & 0,00 & 2 & 2,90 & 28 & 41,2 & 38 & 55,9 & 4,53 & \multirow{3}{*}{4,49} \\
\hline & Y3.2 & 0 & 0,00 & 0 & 0,00 & 4 & 5,90 & 28 & 41,2 & 36 & 52,9 & 4,47 & \\
\hline & Y3.3 & 0 & 0,00 & 0 & 0,00 & 3 & 4,40 & 31 & 45,6 & 34 & 50,0 & 4,46 & \\
\hline \multirow{3}{*}{$\begin{array}{l}\text { Responsibilitas } \\
\text { (Y4) }\end{array}$} & Y4.1 & 0 & 0,00 & 0 & 0,00 & 1 & 1,50 & 29 & 42,6 & 38 & 55,9 & 4,54 & \multirow{3}{*}{4,46} \\
\hline & Y4.2 & 0 & 0,00 & 0 & 0,00 & 5 & 7,40 & 27 & 39,7 & 36 & 52,9 & 4,46 & \\
\hline & Y4.3 & 0 & 0,00 & 0 & 0,00 & 5 & 7,40 & 32 & 47,1 & 31 & 45,6 & 4,38 & \\
\hline \multirow{3}{*}{$\begin{array}{c}\text { Akuntabilitas } \\
\text { (Y5) }\end{array}$} & Y5.1 & 0 & 0,00 & 0 & 0,00 & 1 & 1,50 & 21 & 30,9 & 46 & 67,6 & 4,66 & \multirow{3}{*}{4,62} \\
\hline & Y5.2 & 0 & 0,00 & 0 & 0,00 & 1 & 1,50 & 26 & 38,2 & 41 & 60,3 & 4,59 & \\
\hline & Y5.3 & 0 & 0,00 & 0 & 0,00 & 4 & 5,90 & 18 & 26,5 & 46 & 67,6 & 4,62 & \\
\hline Publik (Y) & \multicolumn{11}{|c|}{ Rerata Variabel Kinerja Pelayanan } & \multicolumn{2}{|c|}{4,51} \\
\hline
\end{tabular}

Sumber: Data Primer (Kuisioner) diolah, tahun 2019

Berdasarkan rekapitulasi pernyataan atas variabel kinerja pelayanan publik (Y) pada Dinas Rumah Sakit Jiwa Kota Kendari seperti yang disajikan pada Tabel 1.3 diatas, menunjukkan bahwa deskripsi jawaban responden secara keseluruhan tentang kinerja pelayanan publik termasuk dalam kategori sangat setuju/sangat baik dengan nilai rerata 4,51 yang berada pada interval $(4,21-5,0)$. Artinya bahwa mayoritas responden menyatakan secara keseluruhan mengenai kinerja pelayanan publik meliputi; produktivitas, kualitas layanan, responsivitas, responsibilitas dan akuntabilitas sebagai hasil dalam meningkatkan semangat kinerja pada pelayanan publik.

\section{Pembahasan Hasil Penelitian}

\section{a. Hasil Uji Validitas}

Hasil tes validitas dengan menggunakan bantuan program SPSS Versi 21 dapat dilihat sebagai berikut: 
Tabel 1.4 Uji Validitas Variabel

\begin{tabular}{|c|c|c|c|c|}
\hline No & Variabel & No Indikator & $\begin{array}{l}\text { Koefisien } \\
\text { Korelasi }\end{array}$ & Keterangan \\
\hline 1 & \multirow{8}{*}{ Insentif (X1) } & $\mathrm{X} 1.1$ & 0,653 & Valid \\
\hline 2 & & $\mathrm{X} 1.2$ & 0,756 & Valid \\
\hline 3 & & $\mathrm{X} 1.3$ & 0,647 & Valid \\
\hline 4 & & $\mathrm{X} 1.4$ & 0,640 & Valid \\
\hline 5 & & $X 1.5$ & 0,798 & Valid \\
\hline 6 & & X1.6 & 0,711 & Valid \\
\hline 7 & & $\mathrm{X} 1.7$ & 0,704 & Valid \\
\hline 8 & & $\mathrm{X} 1.8$ & 0,671 & Valid \\
\hline 9 & \multirow{15}{*}{$\begin{array}{c}\text { Kinerja Pelayanan } \\
\text { Publik (Y) }\end{array}$} & $\mathrm{Y} 1$ & 0,369 & Valid \\
\hline 10 & & Y2 & 0,399 & Valid \\
\hline 11 & & Y3 & 0,396 & Valid \\
\hline 12 & & Y4 & 0,366 & Valid \\
\hline 13 & & Y5 & 0,339 & Valid \\
\hline 14 & & Y6 & 0,328 & Valid \\
\hline 15 & & Y7 & 0,572 & Valid \\
\hline 16 & & Y8 & 0,511 & Valid \\
\hline 17 & & Y9 & 0,628 & Valid \\
\hline 18 & & Y10 & 0,669 & Valid \\
\hline 19 & & Y11 & 0,662 & Valid \\
\hline 20 & & Y12 & 0,597 & Valid \\
\hline 21 & & Y13 & 0,348 & Valid \\
\hline 22 & & Y14 & 0,303 & Valid \\
\hline 21 & & 15 & 0,502 & Valid \\
\hline
\end{tabular}

Sumber: Data Primer di olah, 2019

Berdasarkan Tabel 1.4 di atas menunjukkan bahwa item variabel insentif (X1) dan kinerja pelayanan publik (Y) memiliki nilai koefisien korelasi product moment dengan kriteria pengujian pada instrumen yang dikatakan valid jika nilai $r \geq 0,30$ (cut of point) atau dalam taraf signifikansi $95 \%$ atau $\alpha=0,05$. (Sugiyono, 2010).

\section{b. Uji Reliabelitas}

Hasil tes reliabilitas dengan menggunakan bantuan program SPSS versi 21 dapat dilihat sebagai berikut:

Tabel 1.5 Uji Reliabel Variabel

\begin{tabular}{cccc}
\hline No & Variabel & $\begin{array}{c}\text { Koefisien } \\
\text { Korelasi }\end{array}$ & Keterangan \\
\hline 1 & Insentif (X1) & 0,771 & Reliabel \\
2 & Kinerja Pelayanan Publik (Y) & 0,717 & Reliabel \\
\hline
\end{tabular}

Sumber: Data Primer di olah, 2019

Berdasarkan Tabel 1.5 diatas menunjukkan bahwa variabel insentif (X1) dan kinerja pelayanan publik (Y) masing-masing memiliki nilai koefisien korelasi sebesar 0,771 dan 0,717 . Hal ini sesuai dengan nilai batas (cut of point) yang diterima untuk tingkat 
Alpha Cronbach adalah $\geq 0,60$ walaupun ini bukan merupakan standar absolut oleh Uma Sekaran (2003).

\section{c. Analisis Regresi Linear Sederhana}

Tabel 1.6

Hasil perhitungan Regresi sederhana

\begin{tabular}{|c|c|c|c|c|c|}
\hline \multirow[b]{2}{*}{ Model } & \multicolumn{2}{|c|}{$\begin{array}{l}\text { Unstandardized } \\
\text { Coefficients }\end{array}$} & \multirow{2}{*}{$\begin{array}{c}\text { Standardized } \\
\text { Coefficients } \\
\text { Beta } \\
\end{array}$} & \multirow[t]{2}{*}{$\mathrm{t}$} & \multirow[t]{2}{*}{ Sig. } \\
\hline & B & $\begin{array}{l}\text { Std. } \\
\text { Error }\end{array}$ & & & \\
\hline $1 \quad$ (Constant) & 43.968 & 5.097 & & 8.627 & 0.000 \\
\hline $\mathrm{X} 1$ & .648 & .139 & .498 & 4.671 & 0.000 \\
\hline
\end{tabular}

Sumber: Hasil Olahan Data SPPS, tahun 2019

Persamaan rumus regresi sederhana dapat diperoleh hasil sebagai berikut:

$$
\mathrm{Y}=43.968+0,648(\mathrm{X} 1)
$$

Berdasarkan Tabel 1.6 diatas menunjukkan bahwa nilai koefisien regresi variabel insentif $\left(b_{1}\right)$ bernilai positif, yaitu 0,648 artinya setiap peningkatan insentif sebesar 1 satuan, maka akan meningkatkan kinerja pelayanan publik sebesar 0,648 satuan dengan asumsi variabel independen lain nilainya tetap

\section{d. Uji t Statistik}

Uji parsial digunakan untuk mengetahui pengaruh masing- masing variabel independen terhadap variabel dependen (Ghazali, 2013), yaitu dengan membandingkan masing-masing nilai $\mathrm{t}$ - statistik dari regresi dengan $\mathrm{t}$-tabel dalam menolak atau menerima hipotesis. Kriteria tersebut sebagai berikut:

1. H0 diterima jika nilai probabilitas ( ignifikan $\mathrm{t}$ ) $>0,05$ dan $p$ value $>0,05$

2. H0 ditolak jika nilai probabilitas (signifikan $\mathrm{t}$ ) $<0,05$ dan $p$ value $<0,05$

Hasil penelitian ini menujukkan bahwa berdasarkan Tabel 1.6 diatas menunjukkan bahwa variabel independen insentif berpengaruh positif dan signifikan terhadap kinerja pelayanan publik. Hal ini dapat dijelaskan sebagai berikut:

- Variabel insentif berpengaruh positif dan signifikan terhadap kinerja pelayanan publik, hal ini dibuktikan dengan nilai t_hitung > t_tabel atau 4,671 > 1,667 dan nilai signifikan sebesar 0,000 lebih kecil dari $\alpha=0,05$ atau $5 \%$. 


\section{e. Koefisien Determinasi $\mathbf{R}^{2}$}

Pada model regresi sederhana, koefisien determinasi $\left(\mathrm{R}^{2}\right)$ digunakan untuk mengukur tingkat kemampuan model dalam menerangkan variasi pada variabel dependen (Ghazali, 2011).

\section{Tabel 1.7}

PengujianKoefisien Determinasi

\begin{tabular}{|c|c|c|c|c|}
\hline \multicolumn{5}{|c|}{ Model Summary } \\
\hline Model & $\mathrm{R}$ & R Square & $\begin{array}{l}\text { Adjusted } \\
\text { R Square }\end{array}$ & $\begin{array}{l}\text { Std. Error of the } \\
\text { Estimate }\end{array}$ \\
\hline 1 & $.498^{\mathrm{a}}$ & .248 & .237 & 3.469 \\
\hline
\end{tabular}

a. Predictor: (Constant), X1

b. Dependent Variable: $Y$

Sumber: Hasil Olahan Data SPPS, tahun 2019

Berdasarkan Tabel 1.7 di atas, menunjukkan bahwa nilai determinan $\mathrm{R}$ adalah sebesar 0,498 mengindikasikan bahwa variabel kinerja pelayanan publik (Y) mampu dijelaskan oleh variabel independen berupa insentif (X1) atau nilainya sebesar 49,8 persen dan sisanya 50,2 persen dijelaskan oleh variabel lain diluar model penelitian ini.

\section{KESIMPULAN DAN SARAN}

Berdasarkan hasil analisis pada bab-bab sebelumnya dapat disimpulkan bahwa, insentif berpengaruh positif dan signifikan terhadap kinerja pelayanan publik. Artinya bahwa Semakin tinggi tingkat insentif maka semakin tinggi pula kinerja pelayanan publik.

Hasil regresi linear sederhana menggunakan rumus $Y=\alpha+\beta X$ dengan bantuan SPSS v.21 dengan perolehan data, konstanta sebesar 43.968, sedangkan koefisien regresi sebesar 0, 648, dengan tingkat signifikan sebesar 0,00 $(<0,05)$, serta $t$ hitung sebesar 4,671( > t tabel sebesar 1,667 dan nilai signifikan berada di angka sebesar 0,000 lebih kecil dari $\alpha=0,05$ atau $5 \%$. Variabel insentif berpengaruh langsung sebesar 49,8 \% terhadap variabel kinerja pelayanan publik. Sehingga hipotesis menyatakan bahwa insentif berpengaruh terhadap kinerja pelayanan publik (H1) diterima.

Adapun beberapa saran yang peneliti dapat sampaikan adalah sebagai berikut:

1. Pada penelitian ini memiliki nilai determinan $\left(R^{2}\right)$ sebesar 49,8 persen dan sisanya 50,2 persen dijelaskan oleh variabel lain diluar model penelitian ini. Oleh karena itu, penelitian selanjutnya dapat menambahkan keragaman variabel penelitian yang dapat meningkatkan kinerja pelayanan publik pada Rumah Sakit Jiwa Kota Kendari. 
2. Bagi penelitian selanjutnya, yang berniat mengadakan penelitian yang sejenis dengan penelitian ini, disarankan agar menambahkan variabel penelitian dan menggunakan analisis regesi berganda.

\section{DAFTAR PUSTAKA}

A.A. Anwar Prabu Mangkunegara. 2001, Manajemen sumber daya manusia perusahaan, Bandung : Remaja Rosdakarya.

Arikunto. 2006. Prosedur Penelitian. Jakarta: Rineka Cipta.

Askara. 2008. Manajemen Sumber Daya Manusia. PT. Bumi Jakarta.

Askara. 2011. Manajemen: Dasar, Pengertian dan Masalah. Jakarta. PT. Bumi Jakarta

Agus Dwiyanto,2010. Mewujudkan Good Governance melalui Pelayanan Publik, Gadjah Mada University Press, Yogyakarta.

Agus Sembiring 2016 Pengaruh insentif dan disiplin terhadap kinerja pegawai Dinas Pendidikan dan Kebudayaan Kabupaten Kutai Timur"

Albion M,J, \& Fogarty G,J. 2000. Factors influencing career decision making in adolescents and adults.Australia: University of Southern Queensland Toowoomba.

Bilson Simamora,2003, Memenangkan Pasar dengan Pemasaran Efektif \&Profitabel,Gramedia Pustaka Utama,Jakarta.

Effendy, Onong Uchjana.2002. Ilmu Komunikasi Teori Dan Praktek. Bandung: PT Remaja Rosdakarya

Emzir, Prof. DR., M.Pd. 2011. Metode Penelitian Pendidikan Kuantitatif dan Kualitatif. Jakarta. Rajawali Press. (akses digoogle)

Hasibuan, Malayu S.P. 2005. Manajemen Sumber Daya Manusia, Edisi Revisi. Bumi Aksara, Jakarta.

Hadari Nawawi.2005. Penelitian Terapan.Yogyakarta:Gajah Mada University Press.

Handoko, T Hani. 2002. Manajemen Personalia dan Sumber Daya Manusia. Yogyakarta : BPFE.

Hasibuan, Malayu. 2006. Manajemen Sumber Daya Manusia. Edisi Revisi. Jakarta : Bumi Aksara.

H. Jakson. 2001. Faktor-faktor yang mempengaruhi Kinerja

http://www. Teori-teory Insentif dan Kinerja. doc.pdf. selasa. (24 Agustus 2018 jam 20:30.)

L. Mathis, Robert \&H. Jackson, John. 2011. Human Resource Management (edisi 10). Jakarta : Salemba Empat

Mahmudi. 2010. Manajemen Keuangan Daerah. Jakarta: Penerbit Erlangga.

Mahsun, Mohamad. 2006. Pengukuran Kinerja Sektor Publik : Cetakan Pertama. Yogyakarta : Penerbit BPFE-Yogyakarta

Mazura 2012 "Pengaruh insentif terhadap kinerja pegawai sipil (Studi kasus pada Badan Kepegawaian Daerah Kabupaten Bengkalis)

Moeheriono. 2010. Pengukuran Kinerja Berbasis Kompetensi. Surabaya: Ghalia Indonesia

Mazura, Skripsi 2012. Pengaruh Insentif terhadap Kinerja Pegawai Sipil (Studi Kasus pada Badan Kepegawaian Daerah Kabupaten Bengkalis). https://www.academia.edu/23717702/pengaruh_insentif_terhadap_kinerja_pegawai_ negeri_sipil_studi_kasus_pada_badan_kepegawaian_daerah_kabupaten_bengkalis

Martoyo, Susilo. 1994. Manajemen Sumber Daya Manusia. Yogyakarta : BPFE 
Mutiara S. Panggabean,2002, Manajemen Sumber Daya Manusia. Ghalia Indonesia, Jakarta.

Nawawi, Hadari. 2005. Manajemen Sumber Daya Manusia. Yogyakarta: Gajah Mada University Press

Prawirosentono, Suyadi. 1999. Manajemen Sumberdaya Manusia : Kebijakan Kinerja Karyawan. Yogyakarta : BPFE.

Rivai. 2004. Penilaian Prestasi Kerja Teori dan Praktek. Jakarta. PT. Ganudra Pustaka Utama

Rusda Khairati 201). Pengaruh insentif dan motivasi kerja pegawai Dinas Pengelolaan Keuangan Daerah Kabupaten Pesisir Selatan

Rusda Khairati, Skripsi 2015. Pengaruh Insentif dan Motivasi Kerja Pegawai Dinas Pengelolaan Keuangan Daerah Kabupaten Pesisir Selatan.

Sarwoto. 2010. Dasar-Dasar Organisasi dan Manajemen. Jakarta:Ghalia Indonesia. Siagian, Sondang. 2007. Fungsi-fungsi manajerial edisi revisi. Jakarta. Bumi Aksara. Sugiyono. 2009. Metode Penelitian Kuantitatif, Kualitatif dan R\&D. Bandung: Afabeta Sugiyono. 2010. Metode Penelitian Pendidikan Pendekatan Kuantitatif, kualitatif, dan $R \& D$. Bandung: Alfabeta.

Sugiyono. 2011. Metode Penelitian Kuantitatif, Kualitatif dan R\&D. Bandung: Afabeta

Sugiyono. 2014. Metode Penelitian Pendidikan Pendekatan Kuantitatif, Kualitatif, dan $R \& D$. Bandung: Alfabeta.

Sedarmayanti. 2001. Sumber Daya Manusia dan Produktivitas Kerja. Bandung: Mandar Maju.

Sedarmayanti.2007.Manajemen Sumber Daya Manusia. Bandung:Refika Aditama.

Serliana 2018. Pengaruh Insentif terhadap Kinerja Pegawai di Badan Pendapatan Daerah Kabupaten Kutai Kartanegara

Siagian, P. Sondang. 2008. Manajemen Sumber Daya Manusia. Jakarta : Bumi Akasara

Sugiyono, Metode Penelitian Kuantitatif, Kualitatif dan R\&D. Bandung: Alfabeta, 2012.

Rivai, Veitzhal. 2004. Manajemen Sumber Daya Manusia Untuk Perusahaan. Jakarta: Murai Kencana.

Rivai, Veitzhal \& Basri. 2005. Peformance Appraisal: Sistem yang tepat untuk Menilai Kinerja Karyawan dan Meningkatkan Daya Saing Perusahan. Jakarta: PT. RajaGrafindo Persada.

Syamsuddinnor. 2014. Pengaruh Pemberian Insentif Dan Disiplin Kerja Terhadap Kinerja Karyawan Pada PT. Ben Line Agencies (Bla) Banjarmasin. Jurnal Volume 6 NOMOR 1 Sekolah Tinggi Ilmu Manajemen Indonesia (STIMI) Banjarmasin. pdf

Wibowo. 2010. Manajemen Kinerja.Jakarta: Rajawali Press.

Wirawan. 2009. Evaluasi Kinerja Sumber Daya Manusia Teori Aplikasi dan Penelitian.Jakarta : Salemba Empat. 